\section{ECCOMAS}

\section{Proceedia}

COMPDYN 2019

$7^{\text {th }}$ ECCOMAS Thematic Conference on Computational Methods in Structural Dynamics and Earthquake Engineering

M. Papadrakakis, M. Fragiadakis (eds.) Crete, Greece, 24-26 June 2019

\title{
SEISMIC ASSESSMENT OF MASONRY CROSS VAULTS THROUGH NUMERICAL NONLINEAR STATIC AND DYNAMIC ANALYSIS
}

\author{
Nicoletta Bianchini $^{* 1 \mathrm{a}}$, Nuno Mendes ${ }^{1 \mathrm{~b}}$, Paulo B. Lourenço ${ }^{1 \mathrm{c}}$, Chiara Calderini ${ }^{2 \mathrm{a}}$ and Mi- \\ chela Rossi ${ }^{2 b}$ \\ ${ }^{1}$ ISISE, Department of Civil Engineering, University of Minho, Guimarães, Portugal \\ e-mail: nicoletta.bianchini@gmail.com; @civil.uminho.pt;
${ }^{2}$ Department of Civil, Chemical and Environmental Engineering (DICCA), Via Montallegro 1, 16145 Genoa, University of Genoa, Italy e-mail: chiara.calderini@unige.it, michela.rossi@dicca.unige.it

\begin{abstract}
Masonry vaults represent a pleasant typology of structural horizontal element in traditional architecture and historical buildings, widespread on a large scale along all the European countries, even those characterized by a high level of seismicity. However, they are some of the most vulnerable structural elements particularly under dynamic actions. Therefore, the assessment of their structural safety and the determination of their stress field is a very important task for preservation of historic buildings. Vaults have been studied from an architectural and structural point of view as sequences of arches, and thus extending the use of bidimensional tools of analysis. This assumption can be reliable for the analysis of barrel vaults, but it is not always the most appropriate solution for investigating more complex vaulted systems with a not negligible three-dimensional behavior.

The paper presents on the analysis of a particular groin vault, typically found in monumental buildings which will be successively tested during an experimental dynamic campaign on the shake table. Among all the failure mechanisms of this type of vault, the shear failure is one of the most frequently recorded during post-earthquake surveys. The activation of the shear response is caused by asymmetric boundary conditions and difference in stiffness between two sides of the vault, as it occurs in groin vaults covering churches aisles characterized by the presence of a perimeter wall on one side and two columns on the other side. The main aim of the paper is to investigate the seismic response of a brick groin vault simulating the boundary conditions and loadings of an aisle in a three naves church prototype. Static and dynamic nonlinear numerical analyses were performed using a finite element model. The boundary conditions simulate from one side the presence of a perimeter wall and from the other side the two columns between the main and the lateral nave. The role of the infill and of the amplification of the seismic input are investigated. The results are analyzed in terms of ultimate displacement capacity, crack pattern and damage mechanisms.
\end{abstract}

Keywords: Masonry Cross Vaults, Historical buildings, Seismic Assessment, FE Modelling, Non-linear Dynamic Analysis.

ISSN:2623-3347 (C) 2019 The Authors. Published by Eccomas Proceedia

Peer-review under responsibility of the organizing committee of COMPDYN 2019. doi: 10.7712/120119.6942.18709 


\section{INTRODUCTION}

Masonry vaults represents one of the most widespread horizontal structural elements in historical buildings. Systematic postearthquake damage surveys in churches and historical constructions have proved the vulnerability of vaults towards dynamic actions. Although understanding the 3D seismic behavior of vaults is of primary importance for preserving our cultural heritage and because of economic and social implications that can be caused by their damage/collapse, the research in this field is still limited. Most of the works in literature were focused on the 2D analysis of vaults modelled as a sequence of arches, under both static and dynamic actions. Considering the 3D response, most of the studies have been addressed in analysing the static behavior of vaults, either by using methods based on limit analysis, such as Thrust Network Methods [1-4] and Finite Element limit analysis approaches [5,6] or FE methods with elasto-plastic or damaging models developed for concrete structures, the use of which was extended to curved structures [7-10]. Only few FE softwares were specifically developed for analysing masonry curved structures [11-13]. Furthermode, the use of Discrete Element methods is proving its efficacy because of their capacity to model the discrete nature of masonry and the possibility of considering large displacements [14-16]. Few researchers analysed the seismic behavior of vaults by simulating seismic actions as differential displacements applied to supports using both numerical [17] and experimental approaches [1820].

This paper focuses on investigating the seismic behavior of a brick masonry groin vault with asymmetric boundary conditions, such as that in the grey box in Figure 1, which is a typical configuration found in vaults covering the lateral aisles of the churches. During seismic events, the lower stiffness of the central nave's colonnade compared to the external walls can lead to differential displacements along the longitudinal direction and, consequently, the development of a shear damage mechanism in the horizontal structural elements (Figure 1a). Static and dynamic non linear analyses were carried out on a cross vault model by using a FE model. The numerical simulation have the main aim of investigating the behavior of a fullscale model of a groin vault that will be tested on a shaking table at the LNEC (National Laboratory for Civil Enginnering, Lisbon, Portugal) within SERA- (Seismology and Earthquake Engineering Research Infrastructure Alliance for Europe) Transnational Access Project.

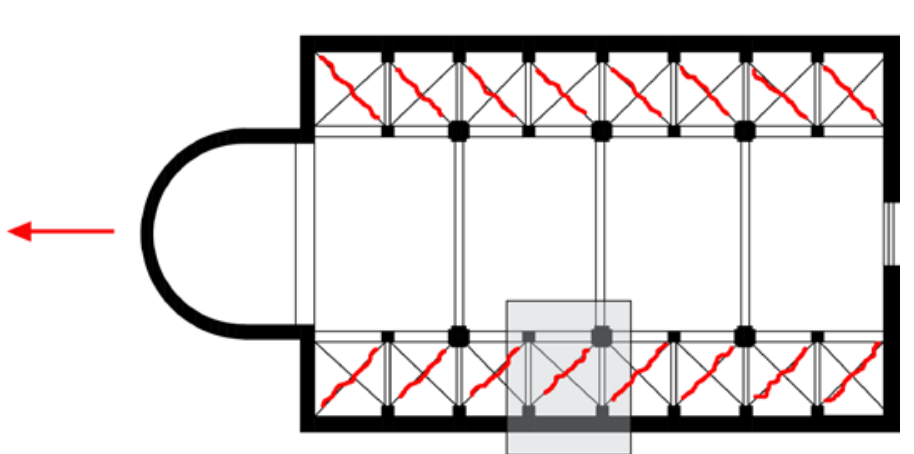

(a)

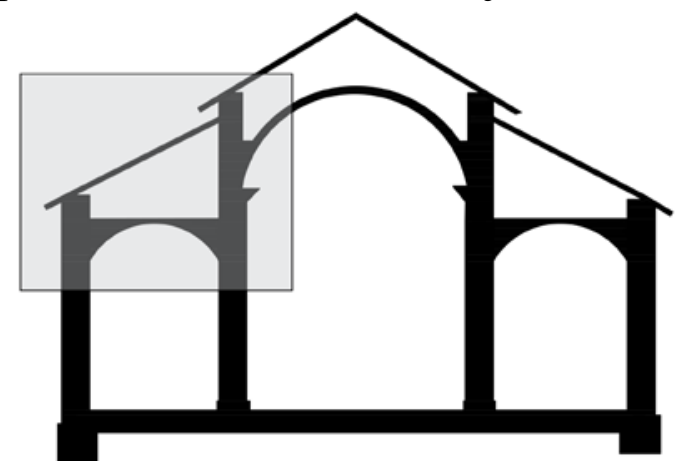

(b)

Figure 1: Plan view (a) and trasversal section (b) of the a common three-naves church. In red the typical shear failure of the lateral nave vaults.

\section{PREPARATION OF THE NUMERICAL MODEL}

In Section 2.1, the physical full-scale groin vault mock-up and the testing setup de-signed for the shake table tests that will be performed at LNEC is described. The numerical model 
adopted for simulating the shake tests is illustrated in Section 2.2, while Section 2.3 defined the seismic input used for the analysis.

\subsection{Geometrical model and skake table testing setup}

The mock-up's geometry and test setup was designed taking into account the dimensions and load capacity of the 3D LNEC shake table. The brick vault model's size is about 3.5x3.5 $\mathrm{m} 2$ in plan and includes two semi-circular barrel vaults with a net span of $2.9 \mathrm{~m}$, with a rise of $0.80 \mathrm{~m}$ and constant thickness of $0.12 \mathrm{~m}$. A plan view and a lateral view of the mock-up are shown in Figure 2 and Figure 3, respectively.

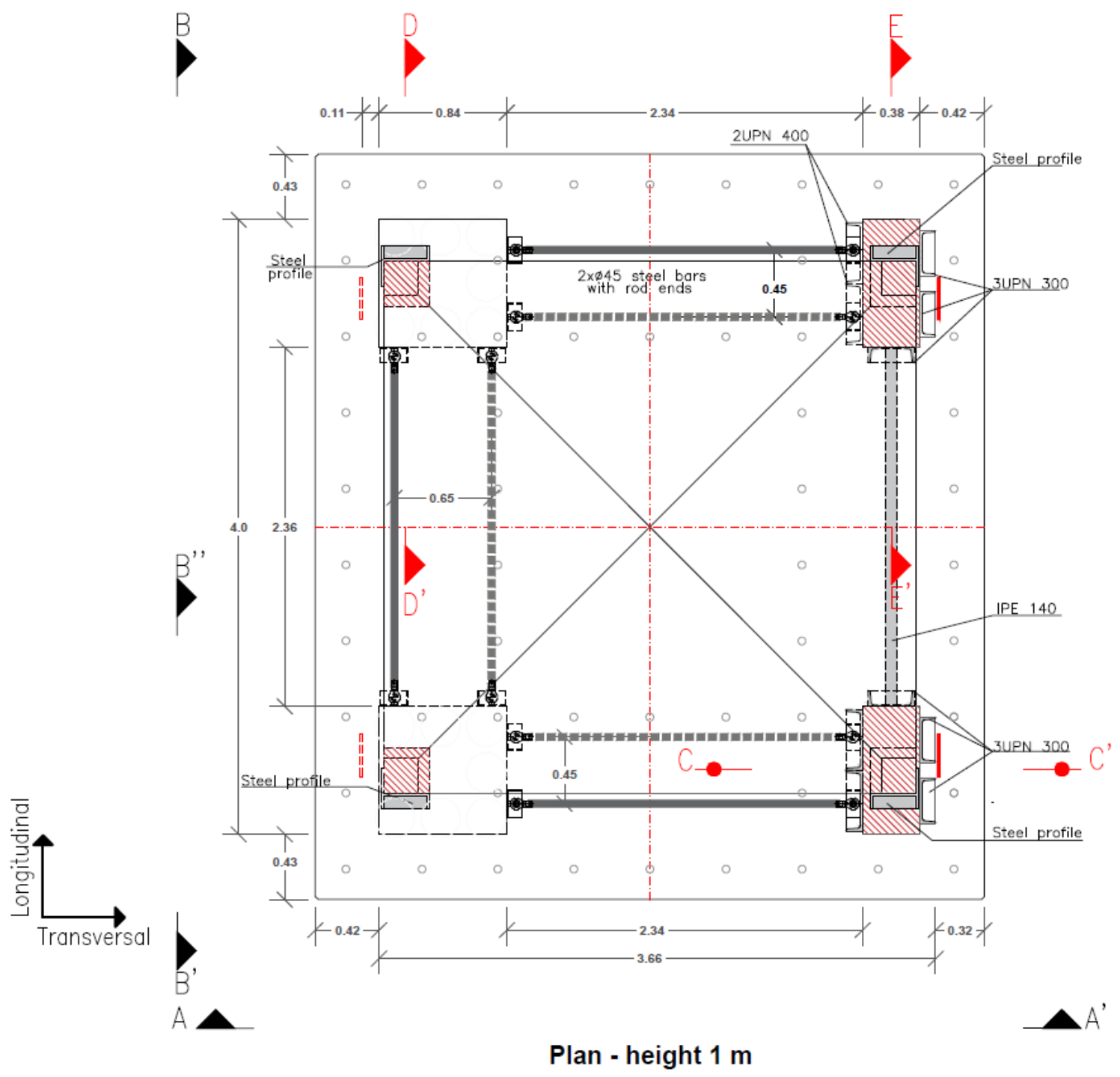

Figure 2: Plan view of the model. Dimension in meters. In red the elements made of masonry, in grey the elements made of steel.

On the side, simulating the lateral continuous wall, the vault's supports will be built on two masonry piers which are clamped on a reinforced concrete slab placed on the shaking table. In order to increase the piers stiffness and to avoid relative displacements between the two piers, a steel frame made with IPE and UPN profiles will be also introduced. 


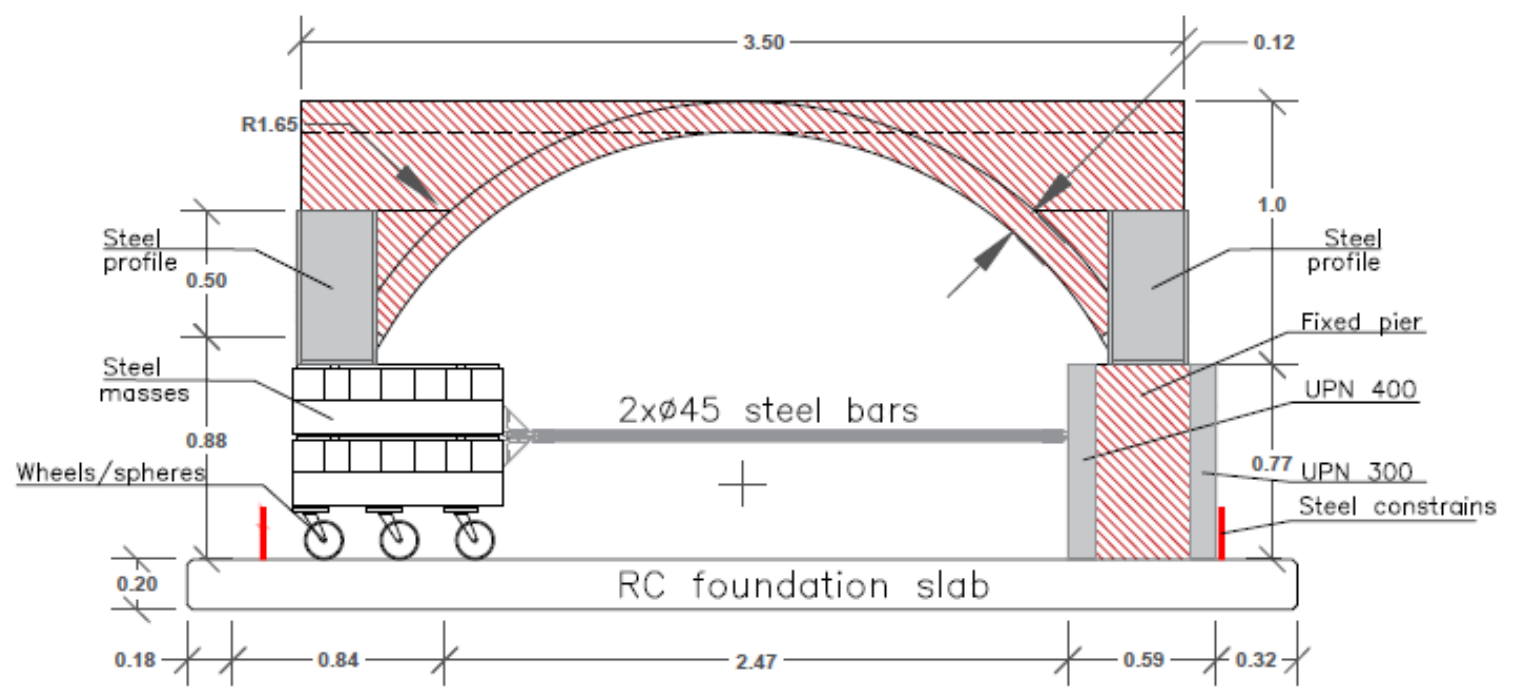

Figure 3: View A-A' of the designed model built on a reinforced concrete slab fixed on the shake table. Dimension in meters. In red the elements made of masonry, in grey the elements made of steel.

On the opposite side that simulates the colonnade, the two supports will be let free to move in all the directions on a movable system of wheels. Moreover, steel masses will be added to the supports (between the vault's abutments and the wheels) in order to simulate the weight of the roof and the roof's supporting wall (see Figure 1b). In addition, in order to avoid any rotational movement of the sup-ports, the four abutments are linked each other by couples of steel rods with rods ends charac-terized by plain spherical bearings. An overlying infill will be built in correspondence of the four vault's corner in order to cover $50 \%$ of the total height of the vault [21]. To avoid local failures at the supports, steel plates were added along the height of the supports and the infill. The steel profiles will aim also to increase the stiffness of the supports and prevent their deformation. The total mass of the mock-up, excluding the steel rods, is equal to 5.15 tons.

\subsection{Description of the numerical model}

The study of the shear failure of the masonry groin vaults was carried out by using an advanced nonlinear finite element solid macro-model, constructed using DIANA FEA [22], considering the geometry that will be adopted for the specimen to test in the LNEC shake table. The vault and the steel elements have been modeled using four-node, three-side isoparametric solid tetrahedron element. It is based on linear interpolation and numerical integration, while the steel cables are modelled as two-node directly integrated (1-point) truss element [22].

The mesh size varies in proportion with the smallest dimension of each element, ranging from $0.01 \mathrm{~m}$ to $0.15 \mathrm{~m}$. The numerical model involves 135,256 nodes and 444,861 degrees of freedom.

In order to replicate the expected behviour of the specimen on the shaking table, the supports of the vault present different boundary conditions. While the fixed piers have all the three translations blocked, the steel masses have only the vertical direction fixed, allowing the movement in the longitudinal and transverse direction when the model is subjected to horizontal static and dynamic loads.

To represent the physical nonlinear behavior, nonlinear properties of the materials were adopted, assuming a Total-Strain Rotating Crack Model [22]. The nonlinear behavior of the masonry includes a parabolic stress-strain relation for compression, while an exponential tension-softening relation was assumed in tension. 
The material and mechanical properties are listed in Table 1.

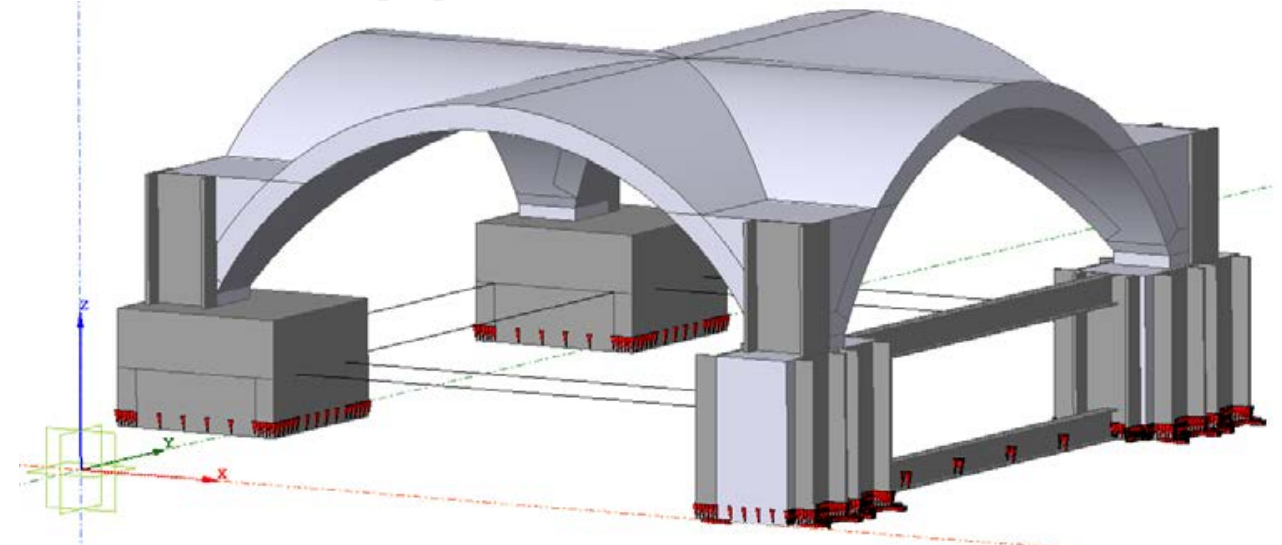

Figure 4: Numerical model and boundary conditions: general view. Dark gray: steel element; light dray: masonry elements.

\begin{tabular}{|c|c|c|}
\hline & Masonry & Steel \\
\hline & $\begin{array}{c}\text { (parabolic and } \\
\text { exponential diagrams) }\end{array}$ & (idealplastic behavior) \\
\hline $\begin{array}{l}\text { Young's modulus [GPa] } \\
\text { [Ga }\end{array}$ & 1.2 & 210.0 \\
\hline Specific weight $\left[\mathrm{kN} / \mathrm{m}^{3}\right]$ & 1.8 & 7.8 \\
\hline Poisson ratio [-] & 0.2 & 0.3 \\
\hline Compressive strength $\left[\mathrm{kN} / \mathrm{m}^{2}\right]$ & 1200.0 & - \\
\hline Compressive fracture energy: $[\mathrm{kN} / \mathrm{m}]$ & 1.92 & - \\
\hline Tensile/Yield strength $\left[\mathrm{kN} / \mathrm{m}^{2}\right]$ & 120.0 & $417.5 \mathrm{E}+03$ \\
\hline Tensile fracture energy: [kN/m] & 3.48E-02 & - \\
\hline
\end{tabular}

Table 1: Material properties adopted in the numerical model.

In the first assessment of the system, the masonry infill and the supports were modelled with linear properties, while the nonlinear behavior was applied only to the shell of the vault. This strategy of modeling aimed to prevent the local failures of the supports, which, if need, can be strengthened in the specimen.

A preliminary linear static analysis, considering only gravitational loads, was performed to check the proper performance of the model, before running the advanced nonlinear analyses. The obtained results were consistent with the expected ones, showing a maximum vertical displacement approximately equal to $0.5 \mathrm{~mm}$ and located at the middle of the vault.

Then, an eigenvalue analysis was performed in order to validate the modal behaviour of the numerical model, and to evaluate the first modes and frequencies in longitudinal direction. The modes in the longitudinal direction correspond to the modes with highest interest for the global dynamic behavior of the vault. Furthermore, a parametric eigenvalue analysis increasing the diameter of the steel rods was carried out, aiming at determining a suitable rod's diameter, able to counteract the rotation around $\mathrm{z}$ axis of the vault's movable supports. This action is also helped by the couple of steel cables both transversal and longitudinal which eliminate the differential rotations in correspondence of the steel masses. The final configuration of the model, with six steel cables has the dynamic properties shown in Figure 5.

The first four modes are related to the vault's global behaviour, while the fifth mode is charac-terized by a local rotation of the steel masses. The global frequencies range from 6.92 $\mathrm{Hz}$ (period of $0.14 \mathrm{~s}$ ) to $26.42 \mathrm{~Hz}$ (period of $0.04 \mathrm{~s}$ ). It can be observed that the first mode frequency, corresponding to the shear mechanism of failure, is very far from the other modes. 
Taking into account the first 25 modes, a cumulative mass participation of about $85 \%$ in each horizontal direction was obtained. Thus, the $1^{\text {st }}$ and the $25^{\text {th }}$ modes were adopted to determine the Rayleigh damping which will be used in the nonlinear dynamic analyses (Section 3.2).

Longitudinal

$6.92 \mathrm{~Hz}$

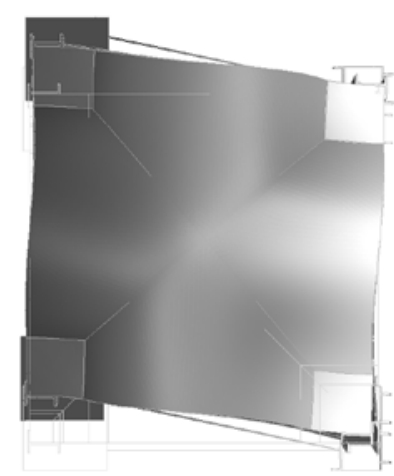

Vertical

$26.42 \mathrm{~Hz}$

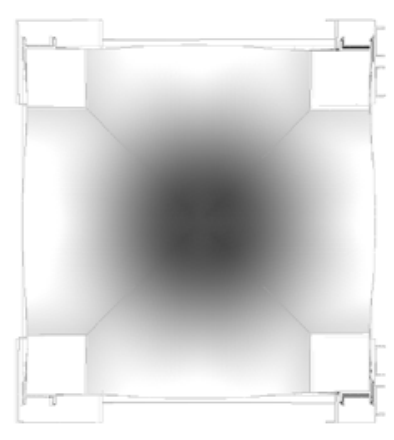

Transversal

$23.42 \mathrm{~Hz}$

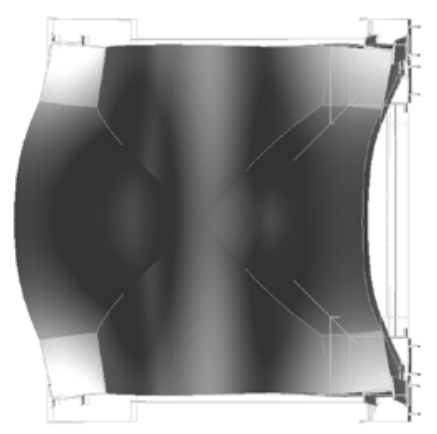

Torsional

$31.93 \mathrm{~Hz}$

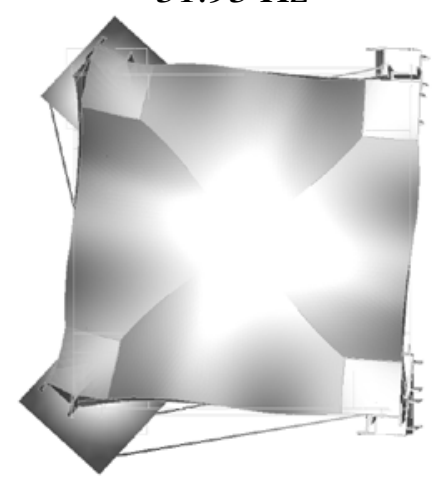

Combined

$24.88 \mathrm{~Hz}$
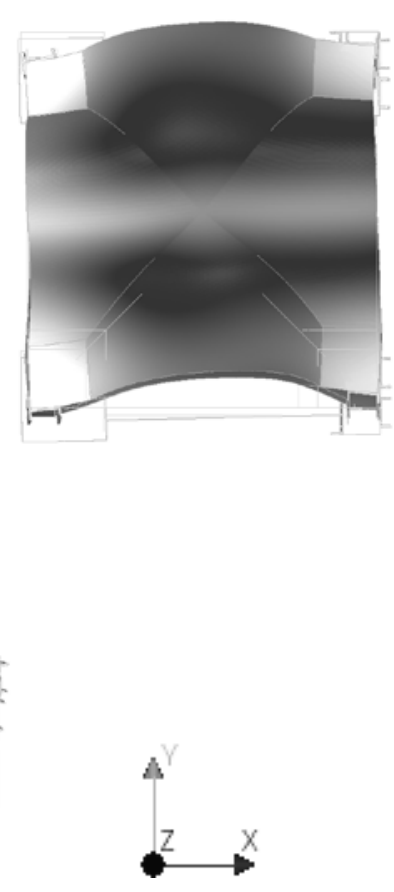

Figure 5: Principal modes of vibration of the numerical model and their frequencies.

\subsection{Input definition}

The real seismic input of Emilia Romagna earthquake (Italy), recorded on $20^{\text {th }}$ May 2012, was applied to the numerical model, considering three directions, namely the transversal (East-West), longitudinal (North-South) and vertical direction. The input, characterized by a $\mathrm{M}_{\mathrm{W}}$ of 5.9, was registered at the station of Mirandola (MRN) located approximately less than $15 \mathrm{~km}$ far from the epicenter.

The choice of adopting this record was due to the fact that the maximum peak ground acceleration (PGA), recorded in Mirandola, is associated to the vertical component which reached an high value of gravity acceleration (Figure 6) [23]. The input is impulsive and it suggests a deeper study of the influence of the sussultatory motion which may be analyzed. This earthquake is impulsive and can be more appropriated to cause damage on the vault. The baseline of the signals was corrected in LNEC-SPA software [24], applying an highpass Fourier filter and the earthquake's duration was dropped selecting the central 20 seconds of its intense phase, respecting the serviceability range of the LNEC shake table. The signals presented in Figure 6 represent the time histories of the accelerations after applying Fourier filter (0.1 and $40 \mathrm{~Hz})$. 
The vertical component of the spectral acceleration has the peak at the very beginning of the signal, in comparison with the horizontal components. All the three components are applied in the numerical and experimental study of this research.
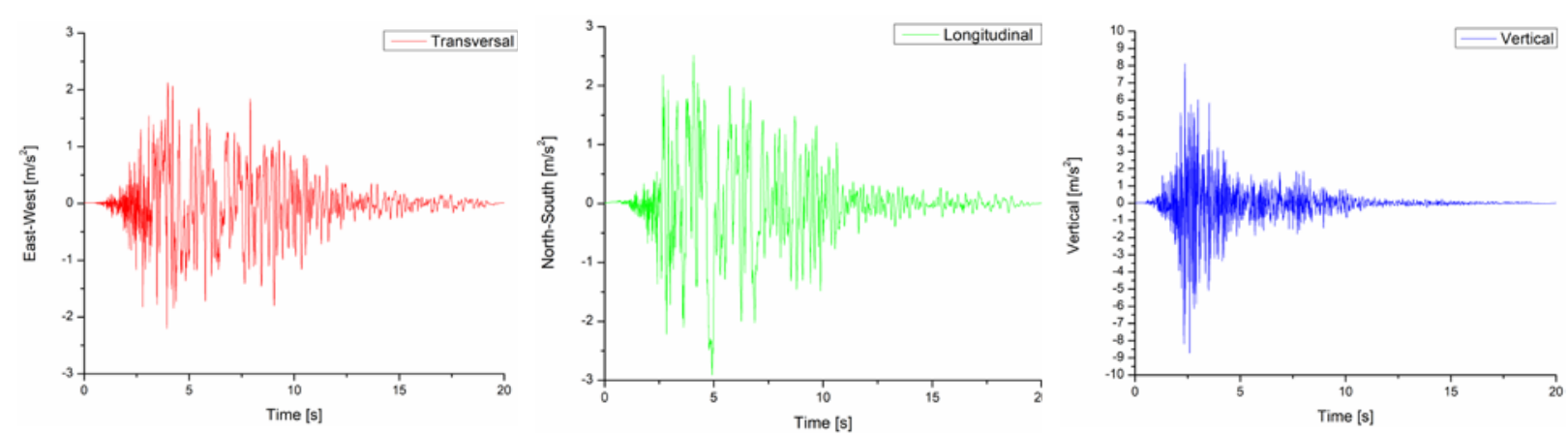

Figure 6: Input signals for time history analysis along East-West (red), North-South (green) and vertical (blue) adopted for the nonlinear dynamic analyses and experimental tests.

\section{SEISMIC ANALYSIS}

\subsection{Nonlinear static analysis}

Before testing the dynamic response of the model, a nonlinear static analysis was performed. Thus, the seismic performance of the vault was evaluated through pushover analysis, applying a monotonic load on the structure in the longitudinal direction (y), after applying the self-weight. A horizontal loading pattern proportional to the mass of the structure was applied in the longitudinal direction. It is noted that, due to the double symmetry of the model there was no need to study both positive and negative direction. Figure 7 presentes the results of the pushover analysis along the longitudinal positive direction. In Figure $7 \mathrm{~b}$, the tensile principal strains are utilized as damage indicator. It can be observed that there is a concentration of damage that starts from the vault's key and continues along its diagonal rib, surrounding the limits of the infill.

It is also possible to compare the load capacity obtained by pushover analysiswith the expected PGA for a specific region. According to [25], the PGA of Mirandola is equal to 0.175g and it is widely lower than the load coefficients the model can bear. The maximum load factor reaches the value of $0.7 \mathrm{~g}$ (Figure 7a). However, it is noted that the action at the base of the vault should take into account the ex-pected amplification in elevation of a church. Moreover, it was observed a general vertical deformation at the central part of the vault due to the relative displacements between the supports (Figure 8). The results shows a crack pattern characterized by four hinges, in agreement with Heyman's theory [26]. 


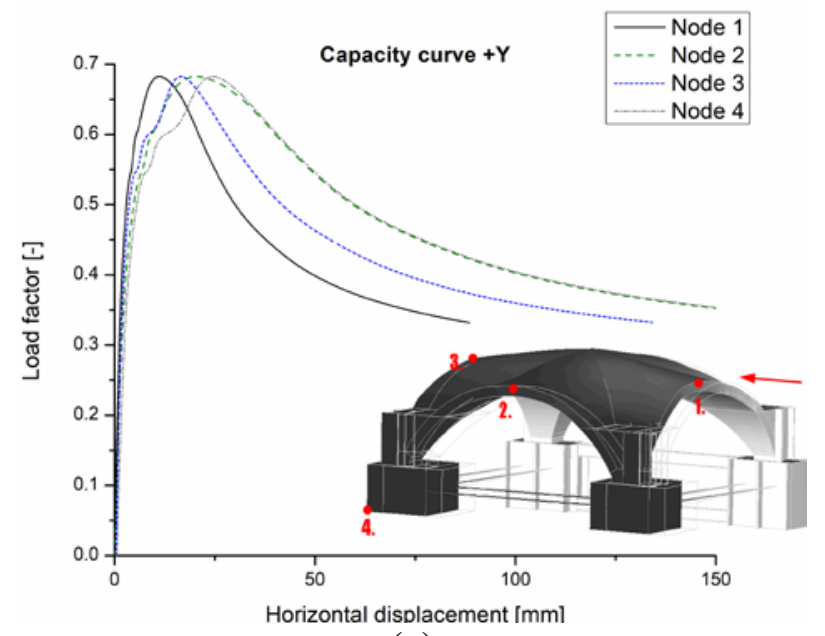

(a)

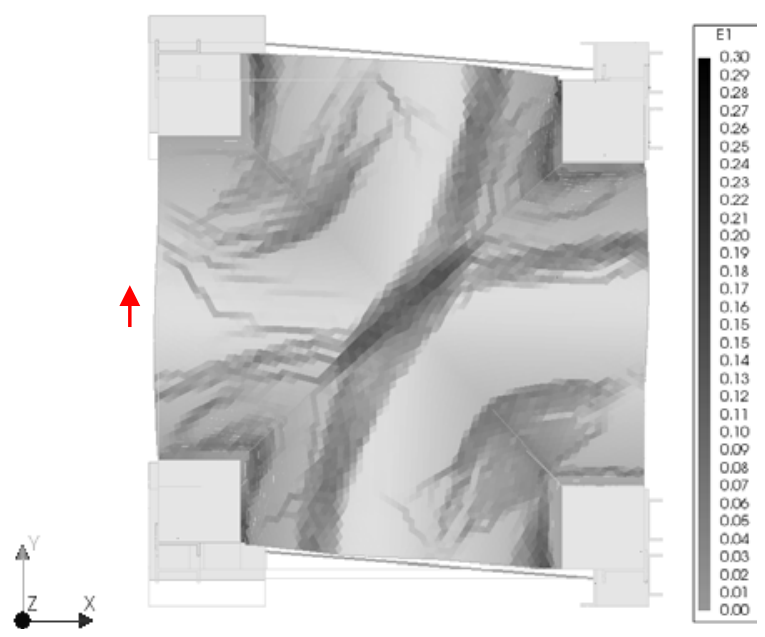

(b)

Figure 7: Pushover analysis in the longitudinal direction +Y: (a) Capacity curved for four control nodes; (b) Principal tensile strains in the top view for a horizontal load equal to $0.35 \mathrm{~g}$ at the end of the capacity curve.

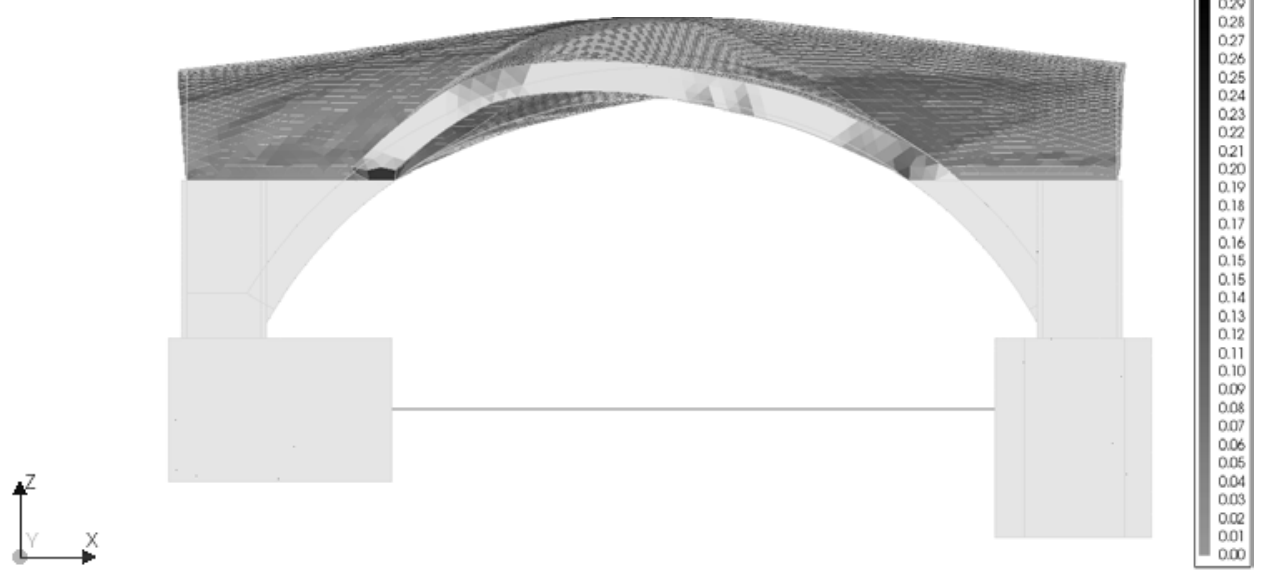

Figure 8: Principal tensile strains of View A-A at the end of the capacity curve.

\subsection{Nonlinear dynamic analysis}

Nonlinear dynamic analysis with time integration was also performed, using the real input described in Section 2.3, with a damping ratio $\xi$ equal to $3 \%$. Thus, damping matrix $\underline{\mathrm{C}}$ (Equation 1) was defined as a combination of Mass matrix $\underline{\mathrm{M}}$ and stiffness matrix $\underline{\mathrm{K}}$ according to Rayleigh viscous damping, defined in [27].

$$
\underline{\mathrm{C}}=\alpha \underline{\mathrm{M}}+\beta \underline{\mathrm{K}}
$$

The two constants, $\alpha$ (2.39) and $\beta$ (0.00012), were based on the results obtained from the eigenvalue analysis, namely considering the first and the twenty-fifth modes as the reference which involve at least $85 \%$ of the mass in the horizontal directions. Another verification of the effective working of the model is represented by plotting the relative displacements observed between the fixed piers and the steel masses (Figure 9). This evaluation shows that the relevant relative displacements are present only along the longitudinal direction (Figure 9a), while, in the transversal direction (Figure 9b), as expected, the steel rods do not allow relative movements. Thus, the damage in the vault is mainly associated to the shear failure. 


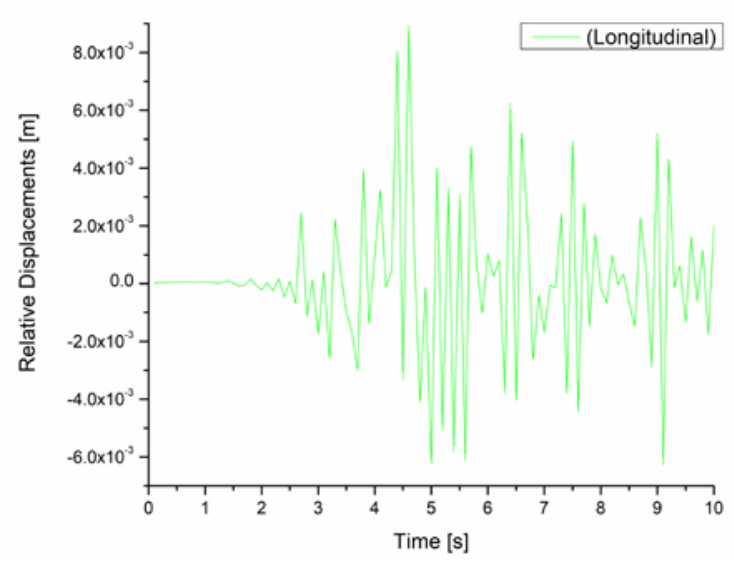

(a)

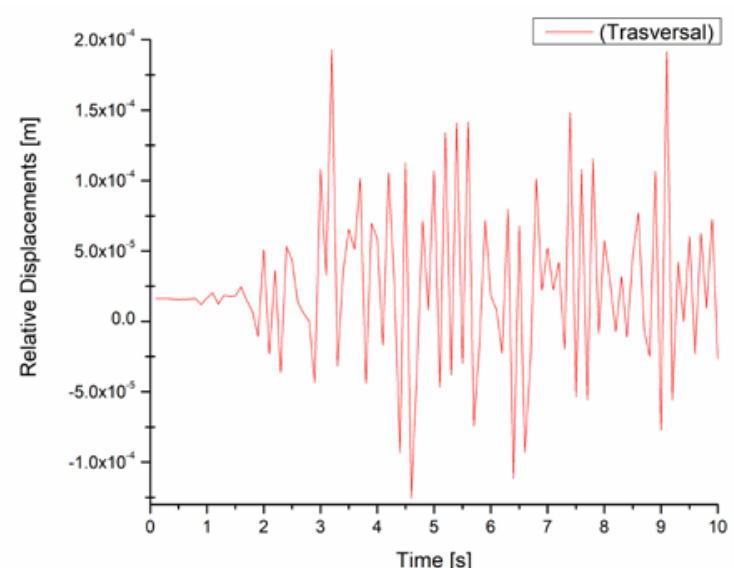

(b)

Figure 9: Relative displacements between the lower corner of the steel mass and the lower corner of the fixed pier for the first $10 \mathrm{~s}$ of the input along the longitudinal (a) and the transversal (b) direction.

Several dynamic analyses were carried out for evaluating the influence of to the vertical component of the earthquake and the infill. Figure 10 shows the cumulative maximum values of the tensile principal strains $\left(\varepsilon_{1}\right)$ at the end of the earthquake $(10 \mathrm{~s})$. The results show that the lack of the infill causes a high damage concentration both along the ribs of the vault and close to the supports (Figure 10b). The presence of the vertical component of the seismic input induces, as expected, more accentuated diagonal cracks, but their location is the same as for the case without the vertical seismic input (Figure 10c).
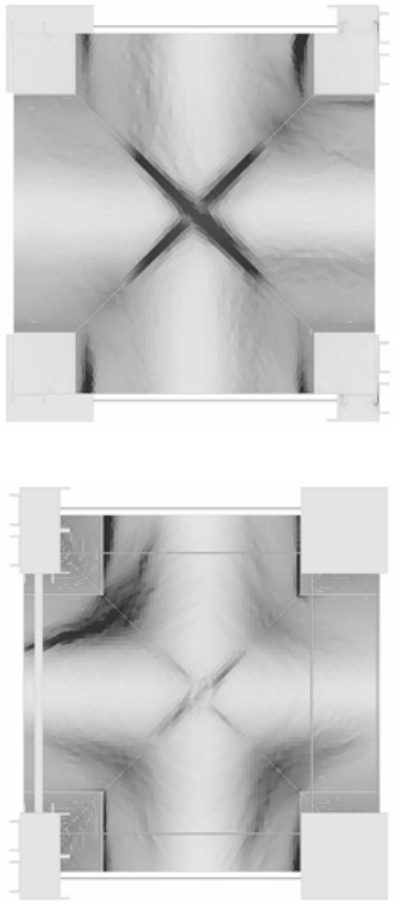

(a) Reference model

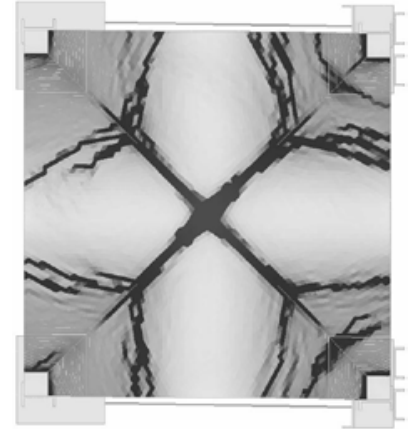

Extrados views

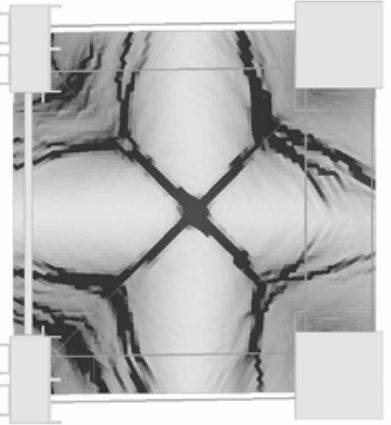

Intrados views

(b) Model without infill
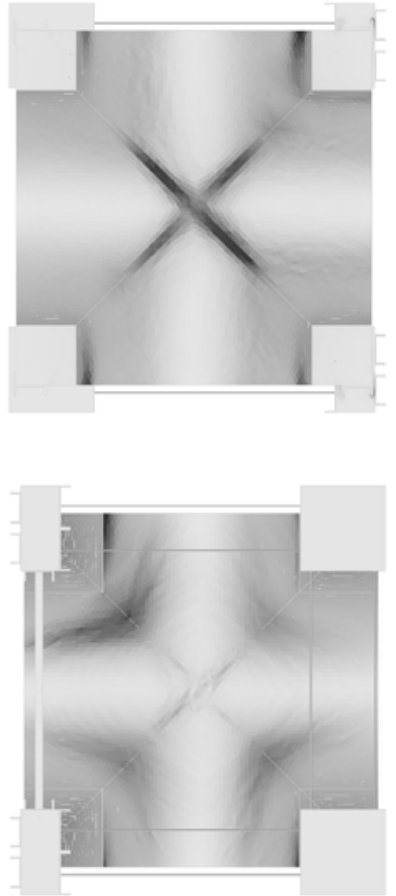

(c) Without vertical component

Figure 10: Tensile principal strains at the time of $10 \mathrm{~s}$.

The reference model was subjected to an incremental increase of the value of PGA until reaching the state close to the ultimate condition. Thus, a numerical incremental dynamic 
analysis (IDA) was performed, applying a positive scale factor to the acceleration time histories in each direction. Expecting a very high time consuming to run the nonlinear dynamic analyses, only the first and more relevant 10 seconds of the earthquake were considered.

Figure 11 illustrates the maximum values of the tensile principal strains $\varepsilon_{1}$ for the six earthquake amplitudes. The results indicate that the first zone with high concentration of strains is at the top of the extrados of the vault and close to the boundaries of the infill. The damage is according to the expected and it shows the typcal shear failure that occurs during a seismic event.

To compare those curves, the load factor in each time step was calculated, i.e. the sum of all the horizontal forces divided by the self weight of the model. It is observed that the maximum value of the load factor for the $100 \%$ of the PGA was about $30 \%$ higher than the one obtained by the static analysis. This is understandable because the nonlinear static analysis forces the shear failure of the vault but also the supports are immediately involved by the sliding behavior at their bases. The dynamic analysis is more representative of the behavior expected in the LNEC shake table and therefore it was utilized to assess the seismic response of the vault.

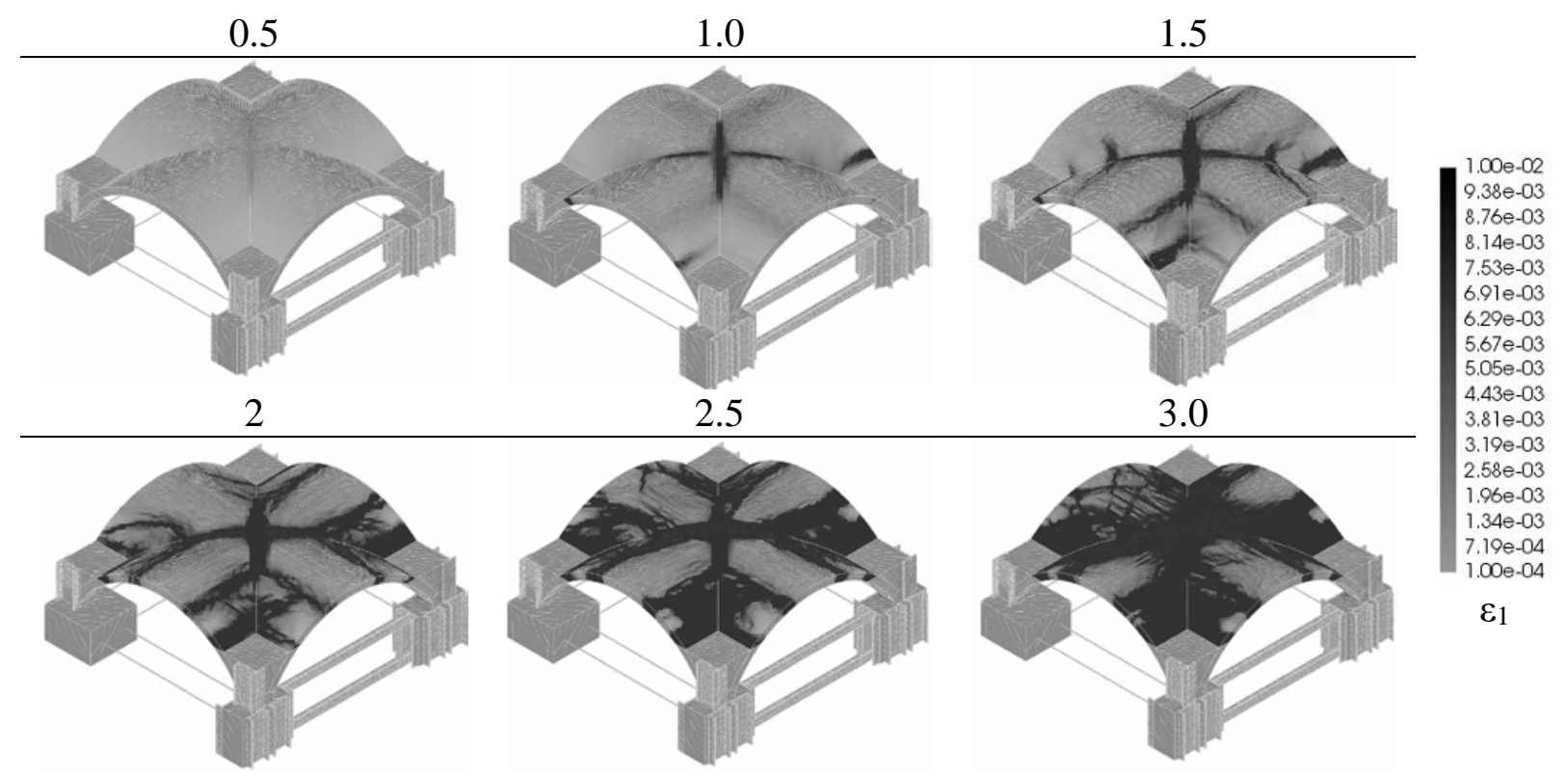

Figure 11: Tensile principal strains of the base model at the time of 10s.

The capacity curves obtained from the pushover analysis and the nonlinear dynamic analyses were compared (Figure 12) [28]. 


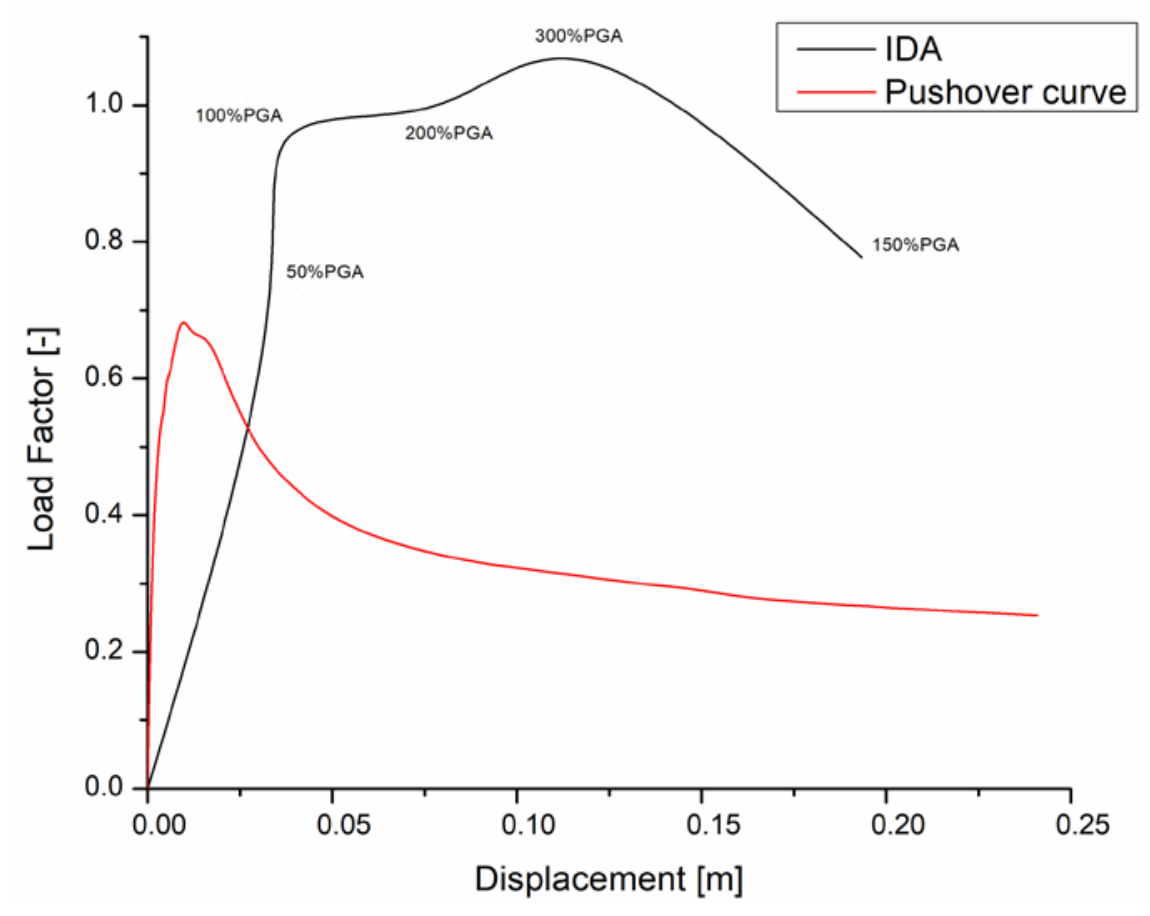

Figure 12: Capacity curve obtained from the pushover and dynamic analyses.

\section{CONCLUSIONS AND FUTURE WORKS}

This paper presents the preliminary study of the behavior of a brick masonry groin vault, before performing shake table tests. The tests will be performed in the 3D LNEC shake table and aim to evaluate the shear failure of the vault. Taking into account the complexity of this study, the design process of thespecimen was evaluated through numerical analysis both static and dynamic. More scenarios, namely considering the role of the infill and the influence of the vertical component, were evaluated, taking into account the seismic input recorded during Emila's Earthquake in 2012.

The eigenvalues analysis was performed, allowing to detect the first longitudinal mode, associated to the shear failure of the vault.

Furthermore, the direct comparison between static and dynamic results lead to the following conclusions: (a) the static configuration was utilized to design the first setup of the model, but it was low indicative of the expected dynamic response that will occur on the shake table; (b) the shear failure was obtained by the last configuration of the model and the main concentrations of damage occured along the rib of the vault; (c) the role of the infill was favorable to avoid a localized damage close to the supports, since it increased the effective thickness of the vault; making the model stiffer and more resistant; (d) the vertical component of the earthquake caused a more significant damage, but it did not bring different concentrations of strains.

Moreover, it is important to highlight that the concentration of strains was mainly located along the solid elements which were modelled with the nonlinear material behavior. Future investigations should assume the non linear of all the masonry elements for nonlinear dynamic analyses, aiming at evaluating whether severe damage may occurs also at the sup-ports of the vault. These analyses may be useful to evaluate the necessity of strenghening the piers of the specimen for the shake table tests.

Another futher development of the numerical study, it is the definition of the expected acceleration amplification at the level of the base of vault for a church. This amplification should be considered for the seismic assessement of the dynamic performance of the vault. 


\section{REFERENCES}

[1] P. Block, T. Ciblac, J. Ochsendorf, Real-time limit analysis of vaulted masonry buildings, Computers and Structures, 84(29-30), 1841-1852, 2006.

[2] F. Fraternali, A thrust network approach to the equilibrium problem of unreinforced masonry vaults via polyhedral stress functions. Mechanics Research Communications, 37(2), 198-204, 2010.

[3] M. Angelillo, E. Babilio, A. Fortunato, Singular stress fields for masonry-like vaults, Continuum Mechanics and Thermodynamics, 25(2-4), 423-441, 2013.

[4] P. Block, L. Lachauer, Three-dimensional funicular analysis of masonry vaults, $\mathrm{Me}$ chanics Research Communications, 56, 53-60, 2014.

[5] G. Milani, A. Tralli, A simple meso-macro model based on SQP for the non-linear analysis of masonry double curvature structures, International Journal of Solids and Structures, 49(5), 808-834, 2012.

[6] A. Chiozzi, G. Milani, A. Tralli, A Genetic Algorithm NURBS-based new approach for fast kinematic limit analysis of masonry vaults, Computers and Structures, 182, 187204, 2017.

[7] G. Creazza, A. Saetta, R. Matteazzi, R. Vitaliani, Analyses of masonry vaults: a macro approach based on three-dimensional damage model. J. Struct. Eng., 128(5), 646-654, 2002.

[8] C. Calderini, S. Lagomarsino, The effect of the masonry pattern on the global behaviour of vaults. Proceedings of the 4th International Conference on Structural Analysis of Historic Construction, Padova, Italy, 2004.

[9] D. D'Ayala and E. Tomasoni, Three-dimensional analysis of masonry vaults using limit state analysis with finite friction, Int. J. Archit. Heritage, 5(2), 140-171, 2011.

[10] D. Theodossopoulos, B.P. Sinha, A.S. Usmani, and A.S.J. Macdonald, Assessment of the structural response of masonry cross vaults, Strain, 38(3), 119-127, 2012.

[11] P. Lourenço, Computational strategies for masonry structures, PhD Thesis, Delft, 1996.

[12] M. Lucchesi, C. Padovani, G. Pasquinelli, and N. Zani, On the collapse of masonry arches, Meccanica, 32, 327-34, 1997.

[13] M. Lucchesi, C. Padovani, G. Pasquinelli, and N. Zani, Statics of masonry vaults, constitutive model and numerical analysis, J Mechan Mater Struct, 2(2), 221-244, 2007.

[14] T. Van Mele, J. McInerney, M. DeJong, P. Block, Physical and Computational Discrete Modelling of Masonry Vault Collapse. Proceedings of 8th International Conference on Structural Analysis of Historical Constructions, Wroclaw, Poland, 2012.

[15] J. McInerney, M. DeJong, Discrete Element Modelling of Groin Vault Displacement Capacity, International Journal of Architectural Heritage, 9(8), 1037-1049, 2015.

[16] D. Foti, V. Vacca, I. Facchini, DEM modeling and experimental analysis of the static behavior of a dry-joints masonry cross vaults. Construction and Building Materials, 170, 111-120, 2018.

[17] A. Gaetani, P. B. Lourenço, G. Monti, G. Milani, A parametric investigation on the seismic capacity of masonry cross vaults, Engineering Structures, 148, 686-703, 2017. 
[18] M. Rossi, C. Calvo Barentin, T. Van Mele, P. Block, Experimental study on the behaviour of masonry pavilion vaults on spreading supports, Structures, 11, 2017.

[19] M. Rossi, C. Calderini, S. Lagomarsino, Experimental testing of the seismic in-plane displacement capacity of masonry cross vaults through a scale model, Bulletin of Earthquake Engineering, 14(1), 261-281, 2016.

[20] C. Carfagnini, S. Baraccani, S. Silvestri, D. Theodossopoulos, The effects of in-plane shear displacements at the springings of Gothic cross vaults, Construction and Building Materials, 186, 219-232, 2018.

[21] A. Gaetani, Seismic Performance of Masonry Cross Vaults : Learning from Historical Developments and Experimental Testing, PhD Thesis, University of Minho, 2016.

[22] DIsplacement method ANAlyser. Release 10.2. DIANA FEA bv, Delft.

[23] F. Bozzoni, C. G. Lai, and L. Scandella, Preliminary results of ground-motion characteristics', Ann. Geophys., 55(4), 609-614, 2012.

[24] L. A. M. Mendes and A. C. Costa, LNEC-SPA, Signal Processing and Analysis Tools for Civil Engineers - Version 1.0 - Build 12, LNEC Rep. no29/2007-NESDE, 2007.

[25] Norme Tecniche delle Costruzioni, 2018. Decreto Ministeriale. Norme tecniche per le costruzioni. Ministry of Infrastructures and Transportations. G.U. S.O. n.8 on 20/2/2018 (in Italian).

[26] J. Heyman, The stone skeleton: Structural engineering of masonry architecture, Cambridge University Press, 1995.

[27] A. K. Chopra, Dynamic of Structures - Theory and applications to earthquake engineering, 4th Edition, Pearson, 2012.

[28] N. Mendes, Comparison of Different Seismic Nonlinear Analyses of An Ancient Masonry Building, $11^{\text {th }}$ Canadian Masonry Symposium, Toronto, Ontario, 2009. 